\title{
Efficient feeding strategy to enhance the start-up of anaerobic ammonium oxidation process in an anaerobic up-flow biofilm column reactor
}

\begin{abstract}
Anaerobic ammonium oxidation (anammox) performed by bacteria that belong to the Planctomycetes phylum could potentially be applied to treat wastewater with high ammonium content. However, anammox application is hindered by the slow growth of bacteria and nitrite and free ammonia inhibition. Thus, this study aims to enrich anammox culture in a $1.0 \mathrm{~L}$ anaerobic upflow biofilm column reactors equipped with a non-woven fabric material, under three different feeding modes: (i) batch, (ii) fed-batch and (iii) continuous, to enhance the start-up of anammox process. A 16S rDNA gene analysis targeting planctomycetes-anammox bacteria was performed on various sludge sources to screen the appropriate inoculum of anammox microorganisms prior to the enrichment study. A reactor with a continuous mode of feeding showed the most effective consumption of $\mathrm{N}-\mathrm{NH} 4+$ and $\mathrm{N}-\mathrm{NO} 2-$, with the highest nitrogen removal rate of $0.28 \mathrm{~kg} \mathrm{~N} \mathrm{~m}-$ $3 \mathrm{~d}-1$ at $0.6 \mathrm{~d}$ hydraulic retention time and $27^{\circ} \mathrm{C}$, compared to the fed-batch and batch of 0.14 and $0.004 \mathrm{~kg} \mathrm{~N} \mathrm{m-3} \mathrm{d-1,} \mathrm{respectively.} \mathrm{The} \mathrm{enriched} \mathrm{anammox} \mathrm{culture} \mathrm{showed} \mathrm{as} \mathrm{close} \mathrm{to} \mathrm{the}$ 'Candidatus Kuenenia stuttgartiensis' genera based on 16S rDNA analysis. Fluorescence in-situ hybridization analysis targeting the $16 \mathrm{~S}$ rDNA gene of anammox bacteria further confirmed the existence of an anammox population in the enriched culture.
\end{abstract}

Keyword: Anaerobic up-flow; Anammox; FISH; Deammonification; Nitric oxide removal 